\title{
Control of neutrophil inflammation at mucosal surfaces by secreted epithelial products
}

\section{Rose L. Szabady* and Beth A. McCormick}

Department of Microbiology and Physiological Systems, University of Massachusetts Medical School, Worcester, MA, USA

\section{Edited by:}

Rajaraman D. Eri, University of Tasmania, Australia

\section{Reviewed by:}

Joseph N. Blattman, University of Washington, USA

George Hajishengallis, University of

Pennsylvania, USA

*Correspondence:

Rose L. Szabady, Department of Microbiology and Physiological

Systems, University of

Massachusetts Medical School, 368

Plantation Street, AS8-2010,

Worcester, MA 01604, USA

e-mail: rose.szabady@umassmed.edu
The human intestine is a large and delicately balanced organ, responsible for efficiently absorbing nutrients and selectively eliminating disease-causing pathogens. The gut architecture consists of a single layer of epithelial cells that forms a barrier against the food antigens and resident microbiota within the lumen. This barrier is augmented by a thick layer of mucus on the luminal side and an underlying lamina propria containing a resident population of immune cells. Attempted breaches of the intestinal barrier by pathogenic bacteria result in the rapid induction of a coordinated innate immune response that includes release of antimicrobial peptides, activation of pattern recognition receptors, and recruitment of various immune cells. In recent years, the role of epithelial cells in initiating this immune response has been increasingly appreciated. In particular, epithelial cells are responsible for the release of a variety of factors that attract neutrophils, the body's trained bacterial killers. In this review we will highlight recent research that details a new understanding of how epithelial cells directionally secrete specific compounds at distinct stages of the inflammatory response in order to coordinate the immune response to intestinal microbes. In addition to their importance during the response to infection, evidence suggests that dysregulation of these pathways may contribute to pathologic inflammation during inflammatory bowel disease. Therefore, a continued understanding of the mechanisms by which epithelial cells control neutrophil migration into the intestine will have tremendous benefits in both the understanding of biological processes and the identification of potential therapeutic targets.

Keywords: hepoxilin, eicosanoids, neutrophil migration, Salmonella, intestinal inflammation, lipoxygenase, MRP2, lipid chemoattractant

\section{NEUTROPHILS: CRITICAL EFFECTORS OF THE INNATE IMMUNE RESPONSE}

Most microbes encountered are non-pathogenic, and the human intestine is host to trillions of harmless or beneficial bacteria. The challenge for the gut immune system is to detect and defend against pathogenic invaders, while protecting commensals and host cells from a potentially damaging inflammatory response. Neutrophils are phagocytic innate immune cells that provide a first line of defense against bacterial infection [reviewed in (1)]. These cells are characterized by their polymorphic nuclei and short half-life, surviving approximately $9 \mathrm{~h}$ in circulation (2). Neutrophils are key components of the inflammatory response and are recruited following infection or sterile wounding. In addition to providing immune protection when barriers are breached, it has been suggested that neutrophils may contribute directly to resolution and recovery $(3,4)$. Genetic deficiencies in neutrophil function, such as mutations in the NADPH oxidase genes in patients with chronic granulomatous disease, result in severe immune defects and increased sensitivity to microbial infection (5). After migrating to effector sites, neutrophils kill pathogens in two distinct ways. Intracellular killing occurs by engulfment of bacteria and formation of a phagosome, which then fuses with intracellular granules to create a phagolysosome where microbes are killed by oxidative and non-oxidative mechanisms. Neutrophils also contribute to extracellular killing by discharging granular contents, releasing proteases, iron-binding proteins, defensins, and enzymes that catalyze formation of reactive oxygen and nitrogen species [reviewed in (1, 6)]. Additionally, neutrophils release "neutrophil extracellular traps" (NETs), structures made up of bacteria, histones, and attached granule enzymes that combine to disable and kill bacteria $(7,8)$. Once they have achieved their function, neutrophils die via apoptotic or non-apoptotic means and are cleared by macrophages during resolution of infection, although recent studies have challenged this paradigm of one-way neutrophil migration (9).

\section{NEUTROPHIL MIGRATION INTO THE INTESTINE: GETTING TO THE SITE OF INFECTION}

Leukocytes migrate to their sites of activity via a carefully regulated multistep adhesion cascade [reviewed in $(4,10-12)]$. Activated neutrophils first adhere to the endothelial cells that line the blood vessels, and then migrate across the endothelium and through the extracellular matrix to arrive at effector sites within the tissues. This occurs via a stepwise process consisting of tethering and rolling, activation, adhesion, and finally diapedesis. The exit sites for leukocyte emigration are the post-capillary venules, which 
are lined with endothelial cells expressing ligands that facilitate leukocyte adhesion. Neutrophils move through the bloodstream at a high flow rate, and the initial tethering process serves to slow the neutrophil's movement and allow it to "roll" along the endothelial cell surface in order to sample for other potential signals. This tethering occurs via interaction of lectins and lectin receptors, and in the intestine is mediated primarily by the binding of endothelial P-selectin to neutrophil P-selectin glycoprotein ligand 1 (PSGL-1) (13-15). Rolling neutrophils become activated when they encounter endothelium-bound chemokines, leading to signaling through $\mathrm{G}$ protein-coupled receptors (GPCRs). This results in activation of $\beta 2$ (CD18) integrins on the neutrophil surface, which interact with cell adhesion molecules (e.g., ICAM-1) and cause firm adhesion to the endothelium. This binding, though reversible, is stable for many hours and allows the cell to extravasate through the endothelial cell layer in order to reach its target site.

During inflammation of the intestinal mucosa, neutrophils that migrate across the endothelium and through the extracellular matrix to the base of the epithelial layer must undergo an additional transepithelial migration step in order to reach the lumen. Epithelial cells form a tight barrier whose permeability is regulated by the apical junction complex, which consists of proteins from adjacent cells interacting to form the tight junctions and adherens junctions [reviewed in (16)]. Crossing this barrier is necessary for neutrophils to defend against extracellular pathogens in the lumen, and also plays an important role in inflammatory pathology. Infiltration of neutrophils is associated with tissue damage at mucosal surfaces via mechanisms that include increased barrier permeability, epithelial apoptosis, and the release of damaging effectors such as reactive oxygen species and proteases $(3,17)$. Neutrophil accumulation on the basolateral side of the epithelium is insufficient to induce this pathology $(18,19)$, suggesting that the specific process of transepithelial migration is critical to the development of inflammatory pathology. Transepithelial migration shares some features with transendothelial migration, such as involvement of the CD11b/CD18 (Mac-1) integrin (20, 21), but also relies on unique interactions such as binding of CD47 and Sirp- $\alpha$ (22, 23). Meanwhile, neutrophil proteases such as elastase transiently degrade the epithelial tight junctions to permit movement across the paracellular space (24). Following migration, evidence suggests that specific ligands mediate neutrophil adherence to the apical surface before they actively detach in order to enter the lumen (25, 26). The importance of apical attachment of neutrophils is not fully understood, but it may be a strategy to encounter and destroy bacteria that are tightly attached to the epithelium. Indeed, apically attached PMN release inflammatory mediators that modulate epithelial responses (27). Apical attachment may also contribute to pathology during inflammation and promote the formation of crypt abscesses during inflammatory bowel disease (IBD) (25, 26, 28). Moreover, detachment of cells from the apical epithelium may be an important step in the resolution of neutrophilic inflammation (29).

\section{RECRUITMENT OF NEUTROPHILS BY EPITHELIAL-DERIVED CHEMOKINES}

In addition to acting as the physical substrate for transepithelial migration, epithelial cells play a critical role in migration by producing chemotactic signals that recruit neutrophils out of the vasculature. CXC chemokines are the main class of chemoattractant ligands that recruit neutrophils and include CXCL1, CXCL2, CXCL5, CXCL6, and CXCL8, also known as IL8 , the prototypical neutrophil-attracting chemokine. These CXC chemokines bind to the two IL- 8 receptors on the neutrophil surface, CXCR1 and CXCR2, with varying affinities and specificities (30). CXC chemokines can be released by a variety of cell types, including neutrophils themselves (31), but the prototypical pathway involves stimulation of epithelial cells resulting in secretion of IL-8. For example, infection of intestinal epithelial cells (IECs) with pathogenic bacteria results in flagellar stimulation of TLR5, followed by activation of NFkB signaling and upregulation of inflammatory pathways and subsequent IL- 8 secretion $(32,33)$.

It is increasingly appreciated that neutrophils exhibit preferential attraction to specific molecules over others, a concept that has been critical to our understanding of how they can integrate and prioritize multiple chemoattractant gradients. Additionally, the "strength" of a specific chemoattractant to recruit neutrophils depends on the local environment (34). For example, IL- 8 and the other CXC chemokines are sufficient to recruit neutrophils out of the vasculature, but once in the tissues cells will preferentially migrate toward leukotriene $\mathrm{B}_{4}\left(\mathrm{LTB}_{4}\right)$ or the $\mathrm{C} 5 \mathrm{a}$ complement fragment. It seems therefore that IL- 8 is an intermediate-stage chemoattractant, whereas C5a and $\mathrm{LTB}_{4}$ are "end-stage" chemoattractants that guide neutrophils to their final destination $(35,36)$. Formylated peptides such as fMLP are very strong neutrophil chemoattractants. It is thought that, because eukaryotic cells do not synthesize formyl peptides, these can serve as a unique bacterial signal to recruit neutrophils to sites of bacterial infection. Interestingly, mitochondria can also synthesize formylated peptides, possibly as a result of their early bacterial ancestry. Mitochondria-derived formyl peptides are released from dying cells and serve as damage associated molecular patterns (DAMPs) that can activate the immune response (37). Indeed, formylated peptides released by necrotic cells were found to serve as the critical end-stage chemoattractant during sterile inflammation (38). It is similarly possible that during inflammation, necrotic epithelial cells in the intestine release mitochondria-derived formyl peptides that attract neutrophils into the lumen, but this has not yet been demonstrated.

\section{RECRUITMENT OF NEUTROPHILS BY BIOACTIVE LIPIDS}

It had long been assumed that IL- 8 production by epithelial cells was sufficient to drive neutrophil infiltration into the intestine. However, IL- 8 undergoes polarized secretion from the basolateral surface of the epithelial cell and is too large to diffuse across the tight junctions into the lumen. In vitro findings confirm that although IL-8 is important for formation of a haptotactic gradient that guides neutrophils through the tissue to the basal epithelium, it is insufficient to drive the final transmigration step across the epithelial barrier $(39,40)$. In addition, mice overexpressing IL-8 specifically in IECs had increased recruitment of neutrophils to the epithelium, but in the absence of further inflammatory stimulus cells did not cross into the lumen 
or induce pathology (19), suggesting that an additional endstage chemoattractant is required. This hypothesis was confirmed by the discovery that colonization of the epithelium by Salmonella typhimurium stimulates apical secretion of the eicosanoid hepoxilin $\mathrm{A}_{3}\left(\mathrm{HXA}_{3}\right)$, which then recruits neutrophils into the lumen $(40,41)$. Eicosanoids are bioactive lipids that are derived from arachidonic acid and mediate a variety of diverse cellular processes. Arachidonic acid is liberated from the cell membrane via the action of phospholipase A2 and converted into a variety of eicosanoids, including the pro-inflammatory neutrophil chemoattractants such as leukotrienes and hepoxilins as well as the anti-inflammatory lipoxins and resolvins (42). The type of eicosanoid that is produced depends on the activity of oxygenase enzymes with different specificities and sites of expression. For example, 5-lipoxygenase catalyzes the synthesis of proinflammatory leukotrienes and is expressed primarily in leukocytes, although there is some evidence that the 5-lipoxygenase dependent precursor, $\mathrm{LTA}_{4}$, can be processed transcellularly to generate active $\operatorname{LTB}_{4}(42,43)$. Similarly, the anti-inflammatory lipoxins are generated by one of two transcellular mechanisms. $\mathrm{LTA}_{4}$ synthesized by 5 -lipoxygenase in leukocytes can then serve as a substrate for adherent platelet-expressed 12-lipoxygenase, generating lipoxin $\mathrm{A}_{4}\left(\mathrm{LXA}_{4}\right)$ and $\mathrm{LXB}_{4}$. Alternatively, epithelial cells expressing 12-lipoxygenase generate 12-HETE from arachidonic acid, which is then acted on by leukocyte 5-lipoxygenase to generate $\mathrm{LXA}_{4}$ and $\mathrm{LXB}_{4}$ (44). Further work is needed to understand the signals that regulate this process and which pathways are functional during specific inflammatory and pro-resolving conditions.

\section{HEPOXILIN $A_{3}$ IS AN ESSENTIAL PLAYER IN THE FINAL STEP OF NEUTROPHIL MIGRATION INTO THE INTESTINE}

In contrast, $\mathrm{HXA}_{3}$ is formed directly in epithelial cells, from which it is secreted in order to create a chemoattractant gradient that drives neutrophils into the lumen. Arachidonic acid is first converted to 12-(S)HPETE by 12-lipoxygenase, and 12-(S)HPETE is then converted to $\mathrm{HXA}_{3}$ by hepoxilin synthase (45). Specific apical secretion of $\mathrm{HXA}_{3}$ is facilitated by multidrug resistant protein 2 (MRP2), an ATP-binding cassette transporter that is localized specifically to the apical surface of IECs (46). The extracellular $\mathrm{HXA}_{3}$ is freely diffusible across the paracellular space between epithelial cells and forms an apical to basolateral gradient (41). Neutrophils that have been recruited to the basolateral epithelium by IL- 8 and other CXC chemokines can therefore sense the $\mathrm{HXA}_{3}$ gradient and transmigrate across the epithelium into the intestinal lumen. This can lead to host-protective clearance of bacteria during infection, but may also result in localized tissue destruction by neutrophil effectors (Figure 1).

Although many important features of the $\mathrm{HXA}_{3}$ biosynthetic pathway have been elucidated, intriguing questions remain. The $\mathrm{HXA}_{3}$ pathway was first identified as a response of epithelial cells to colonization with S. typhimurium, and was found to be essential for neutrophil transepithelial migration in this model $(40,41)$. Careful experiments identified SipA, a bacterial type III secreted protein, as an inducer of $\mathrm{HXA}_{3}$ secretion and showed that treatment with the purified protein alone was sufficient to induce

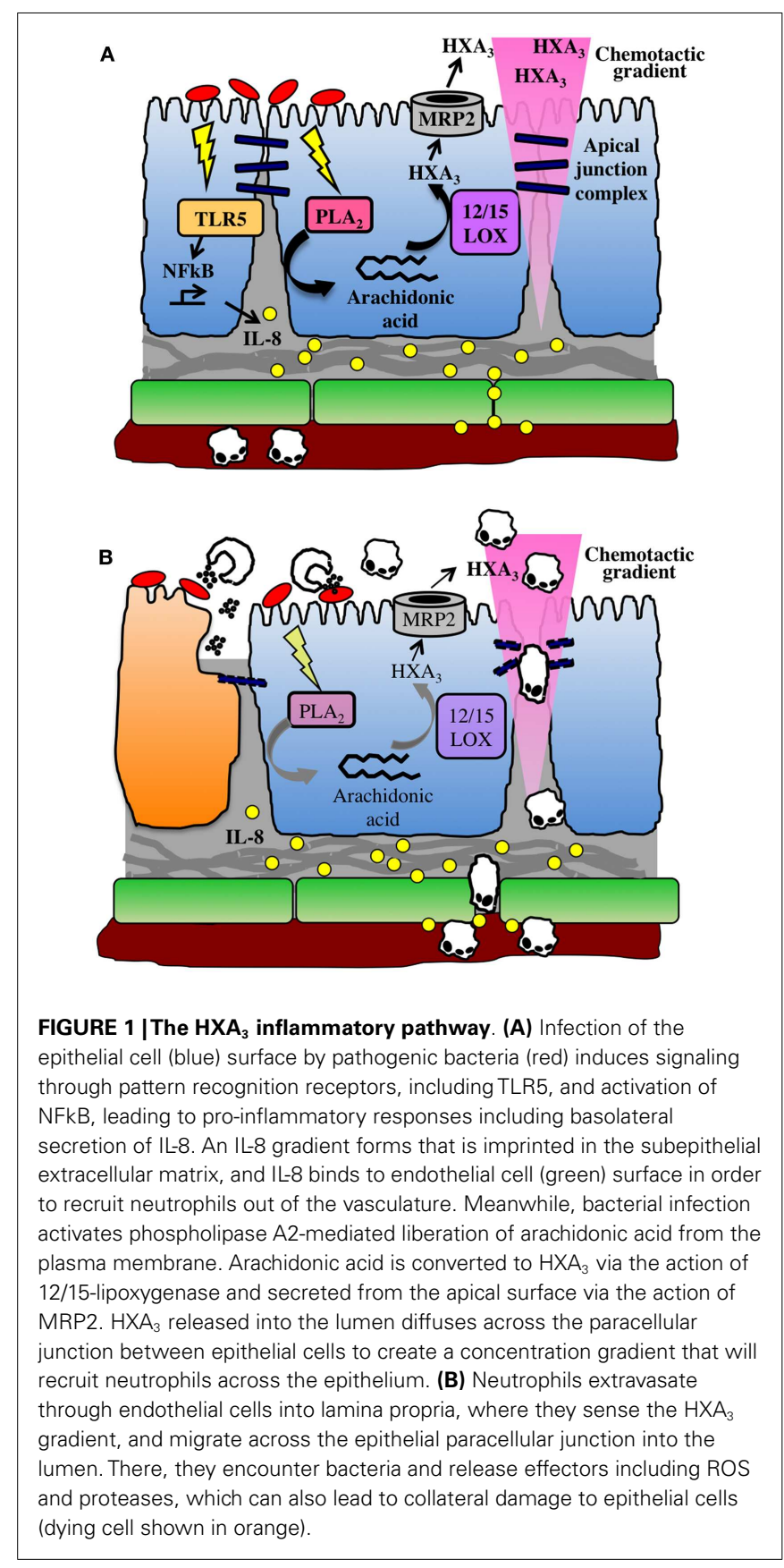

neutrophil transepithelial migration $(47,48)$. Colonization with $S$. typhimurium leads to a SipA-dependent induction of $\mathrm{HXA}_{3}$ synthesis and concurrent upregulation of MRP2 (46). Further details of this pathway continue to be elucidated, including an important role for epithelial caspase- 3 in processing SipA into its active form and the importance of both protein kinase $\mathrm{C}$ activity and ezrin activation in localizing MRP2 to the apical surface (49-51). Unlike IL-8 and fMLP, which also stimulate neutrophil activation, $\mathrm{HXA}_{3}$ seems to act as a pure chemoattractant for neutrophils in the absence of further activation (41). Binding of $\mathrm{HXA}_{3}$ to neutrophils 
induces calcium flux (52) and like other chemokine-receptor interactions, the signal is transduced through a pertussis toxin-sensitive GPCR (40).

While S. typhimurium infection of IECs is the best-studied model of $\mathrm{HXA}_{3}$ secretion, this pathway is in fact a far more universal mechanism by which epithelial cells respond to infection by driving inflammation and neutrophil recruitment. Other intestinal bacterial pathogens, including Shigella flexneri and enteroaggregative Escherichia coli O42 (EAEC), are also able to trigger 12-lipoxygenase and MRP2 dependent synthesis and secretion of $\mathrm{HXA}_{3}$ to drive neutrophil transepithelial migration (53-55). These bacteria do not possess homologs of SipA, and the critical bacterial effectors that activate $\mathrm{HXA}_{3}$ secretion remain to be identified. In the case of EAEC, it has been demonstrated that the aggregative adherence fimbriae (AAF) are necessary for the induction of $\mathrm{HXA}_{3}$-mediated neutrophil migration, and trans-expression of the AAF subunits was sufficient to confer an inflammatory phenotype on non-pathogenic E. coli (55). Interestingly, EAEC do not express a Type III secretion system, while $S$. flexneri do, but unlike $S$. typhimurium invade through the basolateral rather than the apical surface. These data suggest that divergent bacterial effectors must converge at some point leading to $\mathrm{HXA}_{3}$ synthesis and secretion, and the mechanisms underlying this convergence are an area of active investigation.

\section{THE HXA 3 PATHWAY ALSO DRIVES INFLAMIMATION IN THE LUNG MUCOSA}

Further evidence that $\mathrm{HXA}_{3}$ secretion is an important defense mechanism by which epithelial cells communicate to the immune system is evident from the discovery that this pathway is also functional in the lung mucosa. Bacterial pathogens including Pseudomonas aeruginosa and Klebsiella pneumoniae induce neutrophil transepithelial migration in an in vitro model of lung infection (56). Like S. typhimurium, P. aeruginosa induces IL-8 secretion from the basolateral side of the epithelium, and this IL8 is similarly insufficient to drive migration across the epithelial layer. As in the intestine, bacterial infection of the lung epithelial cells triggers PKC activation, 12-lipoxygenase activity, and secretion of $\mathrm{HXA}_{3}(56,57)$. The discovery of the shared reliance on apical secretion of $\mathrm{HXA}_{3}$ to drive the neutrophil inflammatory responses at different mucosal epithelial sites represents a paradigm shift in our understanding of how the epithelium controls the inflammatory response.

\section{A POTENTIAL ROLE FOR HXA - MEDIATED INFLAMIMATION DURING INFLAMMATORY BOWEL DISEASE}

Bacterial infection of the mucosal epithelium triggers a protective acute inflammatory response with neutrophil infiltration, and successful resolution of inflammation involves a dampening of the pro-inflammatory response and apoptotic clearance of inflammatory cells $(3,4)$. However, continuing pathologic inflammation is a hallmark of chronic inflammatory conditions such as IBD. While IBD is thought to result from the combination of an underlying genetic susceptibility and an environmental trigger, a specific bacterial pathogen has yet to be associated with the disease. More recently, it has been hypothesized that IBD may be associated with a "keystone pathogen," a low abundance member of the microbiota that induces or promotes a dysbiotic state that results in inflammatory pathology (58). Patients with ulcerative colitis (UC) and Crohn's disease exhibit specific pathology associated with continued damaging neutrophil infiltration, including crypt abscesses in Crohn's and mucosal ulceration in UC (59). We have identified a role for the $\mathrm{HXA}_{3}$ pathway in mouse models of IBD as well as in association with human disease, suggesting that this pathway is a universal driver of intestinal inflammation beyond the acute response to infection with pathogenic bacteria. MRP2 expression at the epithelial surface is upregulated during chronic intestinal inflammation induced by CD45RBhi T cell transfer colitis in mice. Similarly, colonic biopsies from patients with active UC and Crohn's disease demonstrate increased MRP2 staining at the epithelial surface (46). Furthermore, inhibition of 12-lipoxygenase activity with baicalin significantly reduced inflammatory pathology in $\mathrm{T}$ cell transfer colitis (46). These data suggest that $\mathrm{HXA}_{3}$ is in fact a critical driver of the continued infiltration of neutrophils into the intestine during colitis that leads to damaging inflammatory pathology.

A critical question, then, is what are the pathways that normally regulate $\mathrm{HXA}_{3}$-induced inflammation, and how do these pathways become dysregulated during chronic inflammation? It is increasingly appreciated that resolution of inflammation is not a passive process, but rather an active one that relies on specific pro-resolving mediators. This category includes a wide variety of lipid mediators derived from arachidonic acid or polyunsaturated fatty acids, including the lipoxins, resolvins, neuroprotectins, and maresins [reviewed in $(44,60)]$. These lipids are largely synthesized by macrophages and monocytes that infiltrate during the resolution phase, some by way of a two-part transcellular biosynthesis as described above. It has not been conclusively demonstrated whether resolvins can be generated transcellularly or directly by mucosal epithelial cells. Several of these compounds, including $\mathrm{LXA}_{4}$ and resolvin D1, seem to act in opposition to the classical chemoattractant pathway by binding to GPCRs and transducing a stop signal for migratory cells $(61,62)$. It will be interesting to determine whether this stop signal is functional in the case of $\mathrm{HXA}_{3}$-mediated migration. In vitro, IECs express ChemR23, the receptor for resolvin E1 (RvE1), and RvE1 binding can induce anti-inflammatory effects $(29,63)$. It would be interesting to determine whether RvE1 also suppresses $\mathrm{HXA}_{3}$ biogenesis. Known anti-inflammatory cytokines such as IL-10 are other potentially interesting candidates. It is clear that a major area of continuing research interest lies in understanding how secretion of pro- and anti-inflammatory mediators by epithelial cells is regulated during inflammation. These studies will contribute to our further understanding of how the epithelium plays a critical role in initiating and sustaining the inflammatory immune response, with potential therapeutic implications for a wide variety of inflammatory conditions.

\section{ACKNOWLEDGMENTS}

The authors would like to thank Erik J. Boll for critical reading of the manuscript. 


\section{REFERENCES}

1. Urban CF, Lourido S, Zychlinsky A. How do microbes evade neutrophil killing? Cell Microbiol (2006) 8:1687-96. doi:10.1111/j. 1462-5822.2006.00792.x

2. Dale DC, Liles WC, Llewellyn C, Price TH. Effects of granulocytemacrophage colony-stimulating factor (GM-CSF) on neutrophil kinetics and function in normal human volunteers. Am J Hematol (1998) 57:7-15. doi:10.1002/(SICI) 1096-8652(199801)57:1<7::AID$\mathrm{AJH} 2>3.0 . \mathrm{CO}$;2-0

3. Fournier BM, Parkos CA. The role of neutrophils during intestinal inflammation. Mucosal Immunol (2012) 5:354-66. doi:10.1038/mi. 2012.24

4. Kolaczkowska E, Kubes P. Neutrophil recruitment and function in health and inflammation. Nat Rev Immunol (2013) 13:159-75. doi:10. 1038/nri3399

5. Martire B, Rondelli R, Soresina A, Pignata C, Broccoletti T, Finocchi $\mathrm{A}$, et al. Clinical features, longterm follow-up and outcome of a large cohort of patients with chronic granulomatous disease: an Italian multicenter study. Clin Immunol (2008) 126:155-64. doi:10.1016/j. clim.2007.09.008

6. Nathan C. Neutrophils and immunity: challenges and opportunities. Nat Rev Immunol (2006) 6:173-82. doi: $10.1038 /$ nril785

7. Brinkmann V, Reichard U, Goosmann C, Fauler B, Uhlemann Y, Weiss DS, et al. Neutrophil extracellular traps kill bacteria. Science (2004) 303:1532-5. doi:10. 1126/science.1092385

8. Yipp BG, Petri B, Salina D, Jenne $\mathrm{CN}$, Scott BNV, Zbytnuik LD, et al. Infection-induced NETosis is a dynamic process involving neutrophil multitasking in vivo. Nat Med (2012) 18:1386-93. doi:10. 1038/nm.2847

9. Mathias JR, Perrin BJ, Liu T, Kanki J, Look AT, Huttenlocher A. Resolution of inflammation by retrograde chemotaxis of neutrophils in transgenic zebrafish. J Leukoc Biol (2006) 80:1281-8. doi:10.1189/jlb.0506346

10. Butcher EC, Picker LJ. Lymphocyte homing and homeostasis. Science (1996) 272:60-6. doi:10.1126/ science. 272.5258 .60

11. von Andrian UH, Mempel TR. Homing and cellular traffic in lymph nodes. Nat Rev Immunol (2003) 3:867-78. doi:10.1038/nri1222

12. Petri B, Phillipson M, Kubes P. The physiology of leukocyte recruitment: an in vivo perspective. Mian Yi Xue Za Zhi (2008) 180:6439-46.

13. Norgard KE, Moore KL, Diaz S, Stults NL, Ushiyama S, McEver $\mathrm{RP}$, et al. Characterization of a specific ligand for P-selectin on myeloid cells. J Biol Chem (1993) 268:12764-74.

14. Hidalgo A, Peired AJ, Wild MK, Vestweber D, Frenette PS. Complete identification of Eselectin ligands on neutrophils reveals distinct functions of PSGL-1, ESL-1, and CD44. Immunity (2007) 26:477-89. doi:10.1016/j.immuni.2007.03.011

15. Sperandio M. Selectins and glycosyltransferases in leukocyte rolling in vivo. FEBS $J$ (2006) 273:437789. doi:10.1111/j.1742-4658.2006. 05437.x

16. Chin AC, Parkos C. Pathobiology of neutrophil transepithelial migration: implications in mediating epithelial injury. Annu Rev Pathol (2007) 2:111-43. doi:10.1146/ annurev.pathol.2.010506.091944

17. Nusrat A, Parkos CA, Liang TW, Carnes DK, Madara JL. Neutrophil migration across model intestinal epithelia: monolayer disruption and subsequent events in epithelial repair. Gastroenterology (1997) 113:1489-500. doi:10.1053/ gast.1997.v113.pm9352851

18. Nash S, Stafford J, Madara JL. Effects of polymorphonuclear leukocyte transmigration of cultured intestinal epithelial monolayers. J Clin Invest (1987) 80:1104-13. doi:10. 1172/JCI113167

19. Kucharzik T, Hudson JT, Lügering A, Abbas JA, Bettini M, Lake JG, et al. Acute induction of human IL8 production by intestinal epithelium triggers neutrophil infiltration without mucosal injury. Gut (2005) 54:1565-72. doi:10.1136/gut.2004. 061168

20. Liu Y, O’Connor MB, Mandell KJ, Zen K, Ullrich A, Bühring $\mathrm{H}$ $\mathrm{J}$, et al. Peptide-mediated inhibition of neutrophil transmigration by blocking CD47 interactions with signal regulatory protein alpha. Mian Yi Xue Za Zhi (2004) 172:2578-85.

21. Parkos CA, Delp C, Arnaout MA, Madara JL. Neutrophil migration across a cultured intestinal epithelium. J Clin Invest (1991) 88:160512. doi:10.1172/JCI115473

22. Liu Y, Bühring H-J, Zen K, Burst SL, Schnell FJ, Williams IR, et al. Signal regulatory protein (SIRPalpha), a cellular ligand for CD47, regulates neutrophil transmigration. $J$
Biol Chem (2002) 277:10028-36. doi:10.1074/jbc.M109720200

23. Parkos CA, Colgan SP, Liang TW, Nusrat A, Bacarra AE, Carnes $\mathrm{DK}$, et al. CD47 mediates postadhesive events required for neutrophil migration across polarized intestinal epithelia. J Cell Biol (1996) 132:437-50. doi:10.1083/jcb.132.3. 437

24. Ginzberg HH, Cherapanov V, Dong Q, Cantin A, Christopher AG, Shannon PT, et al. Neutrophil-mediated epithelial injury during transmigration: role of elastase. Am J Physiol Gastrointest Liver Physiol (2001) 281:705-17.

25. Brazil JC, Lee WY, Kolegraff KN, Nusrat A, Parkos CA, Louis NA. Neutrophil migration across intestinal epithelium: evidence for a role of CD44 in regulating detachment of migrating cells from the luminal surface. Mian Yi Xue Za Zhi (2010) 185:7026-36. doi:10.4049/ jimmunol.1001293

26. Lawrence DW, Bruyninckx WJ, Louis NA, Lublin DM, Stahl GL, Parkos CA, et al. Antiadhesive role of apical decay-accelerating factor (CD55) in human neutrophil transmigration across mucosal epithelia. J Exp Med (2003) 198:999-1010. doi:10.1084/jem.20030380

27. Madara JL, Patapoff TW, Gillececastro B, Colgan SP, Parkos CA, Delp C, et al. 5'-Adenosine monophosphate is the neutrophil-derived paracrine factor that elicits chloride secretion from T84 intestinal epithelial cell monolayers. J Clin Invest (1993) 91:2320-5. doi:10. 1172/JCI116462

28. Reaves TA, Colgan SP, Selvaraj P, Pochet MM, Walsh S, Nusrat A, et al. Neutrophil transepithelial migration: regulation at the apical epithelial surface by Fc-mediated events. Am J Physiol Gastrointest Liver Physiol (2001) 280:746-54.

29. Campbell EL, Louis NA, Tomassetti SE, Canny GO, Arita M, Serhan $\mathrm{CN}$, et al. Resolvin E1 promotes mucosal surface clearance of neutrophils: a new paradigm for inflammatory resolution. FASEB $J$ (2007) 21:3162-70. doi:10.1096/fj. 07-8473com

30. Stillie R, Farooq SM, Gordon JR, Stadnyk AW. The functional significance behind expressing two IL-8 receptor types on PMN. J Leukoc Biol (2009) 86:529-43. doi:10.1189/ jlb.0208125

31. Altstaedt J, Kirchner H, Rink L. Cytokine production of neutrophils is limited to interleukin-8. Immunology (1996) 89:563-8. doi:10.1046/j.1365-2567.1996.d01784.x

32. Gewirtz AT, Navas TA, Lyons S, Godowski PJ, Madara JL. Cutting edge: bacterial flagellin activates basolaterally expressed TLR5 to induce epithelial proinflammatory gene expression. Mian Yi Xue Za Zhi (2001) 167:1882-5.

33. Yu Y, Zeng H, Lyons S, Carlson A, Merlin D, Neish AS, et al. TLR5-mediated activation of p38 MAPK regulates epithelial IL8 expression via posttranscriptional mechanism. Am J Physiol Gastrointest Liver Physiol (2003) 285:G282-90.

34. Casale TB, Abbas MK, Carolan EJ. Degree of neutrophil chemotaxis is dependent upon the chemoattractant and barrier. Am J Respir Cell Mol Biol (1992) 7:112-7. doi:10.1165/ ajrcmb/7.1.112

35. Foxman EF, Campbell JJ, Butcher EC. Multistep navigation and the combinatorial control of leukocyte chemotaxis. J Cell Biol (1997) 139:1349-60. doi:10.1083/jcb.139. 5.1349

36. Heit B, Tavener S, Raharjo E, Kubes P. An intracellular signaling hierarchy determines direction of migration in opposing chemotactic gradients. J Cell Biol (2002) 159:91-102. doi:10.1083/jcb.200202114

37. Rabiet M-J, Huet E, Boulay F. Human mitochondria-derived $\mathrm{N}$ formylated peptides are novel agonists equally active on FPR and FPRL1, while Listeria monocytogenes-derived peptides preferentially activate FPR. Eur J Immunol (2005) 35:2486-95. doi:10.1002/eji. 200526338

38. McDonald B, Pittman K, Menezes GB, Hirota SA, Slaba I, Waterhouse CCM, et al. Intravascular danger signals guide neutrophils to sites of sterile inflammation. Science (2010) 330:362-6. doi:10.1126/ science.1195491

39. McCormick BA, Hofman ILPM, Kim J, Carnes DK, Miller SI, Madara JL. Surface attachment of Salmonella typhimurium to intestinal epithelia imprints the subepithelial matrix with gradients chemotactic for neutrophils. J Cell Biol (1995) 131:1599-608. doi:10.1083/jcb.131. 6.1599

40. McCormick BA, Parkos CA, Colgan SP, Carnes DK, Madara JL. Apical secretion of a pathogen-elicited epithelial chemoattractant activity in response to surface colonization of intestinal epithelia by Salmonella typhimurium. Mian Yi Xue Za Zhi (1998) 160:455-66. 
41. Mrsny RJ, Gewirtz AT, Siccardi D, Savidge T, Hurley BP, Madara JL, et al. Identification of hepoxilin A3 in inflammatory events: a required role in neutrophil migration across intestinal epithelia. Proc Natl Acad Sci U S A (2004) 101:7421-6. doi: 10.1073/pnas.0400832101

42. Sadik CD, Luster AD. Lipidcytokine-chemokine cascades orchestrate leukocyte recruitment in inflammation. $J$ Leukoc Biol (2012) 91:207-15. doi:10.1189/jlb.0811402

43. Fabre J, Goulet JL, Riche E, Nguyen $\mathrm{M}$, Coggins $\mathrm{K}$, Offenbacher $\mathrm{S}$, et al. Transcellular biosynthesis contributes to the production of leukotrienes during inflammatory responses in vivo. J Clin Invest (2002) 109:1373-80. doi:10.1172/ JCI200214869

44. Chiang N, Arita M, Serhan CN. Anti-inflammatory circuitry: lipoxin, aspirin-triggered lipoxins and their receptor ALX. Prostaglandins Leukot Essent Fatty Acids (2005) 73:163-77. doi:10.1016/j.plefa.2005.05.003

45. Pace-Asciak CR. Hepoxilins: a review on their cellular actions. Biochim Biophys Acta (1994) 1215:1-8. doi:10.1016/00052760(94)90087-6

46. Pazos M, Siccardi D, Mumy KL, Bien JD, Louie S, Shi HN, et al. Multidrug resistance-associated transporter 2 regulates mucosal inflammation by facilitating the synthesis of hepoxilin A3. Mian Yi Xue Za Zhi (2008) 181:8044-52.

47. Lee CA, Silva M, Siber AM, Kelly AJ, Galyov E, McCormick BA. A secreted Salmonella protein induces a proinflammatory response in epithelial cells, which promotes neutrophil migration. Proc Natl Acad Sci U S A (2000) 97: 12283-8. doi:10.1073/pnas.97.22. 12283

48. Wall DM, Nadeau WJ, Pazos MA, Shi HN, Galyov EE, McCormick BA. Identification of the Salmonella enterica serotype typhimurium SipA domain responsible for inducing neutrophil recruitment across the intestinal epithelium. Cell Microbiol (2007) 9:2299-313. doi:10.1111/j. 1462-5822.2007.00960.x

49. Silva M, Song C, Nadeau WJ, Matthews JB, McCormick BA. Salmonella typhimurium SipAinduced neutrophil transepithelial migration: involvement of a PKC-alpha-dependent signal transduction pathway. Am J Physiol Gastrointest Liver Physiol (2004) 286: G1024-31. doi:10.1152/ajpgi. 00299.2003

50. Srikanth CV, Wall DM, MaldonadoContreras A, Shi HN, Zhou D, Demma Z, et al. Salmonella pathogenesis and processing of secreted effectors by caspase3. Science (2010) 330:390-3. doi:10.1126/science.1194598

51. Agbor TA, Demma ZC, Mumy KL, Bien JD, McCormick BA. The ERM protein, ezrin, regulates neutrophil transmigration by modulating the apical localization of MRP2 in response to the SipA effector protein during Salmonella typhimurium infection. Cell Microbiol (2011) 13:2007-21. doi:10. 1111/j.1462-5822.2011.01693.x

52. Dho S, Grinstein S, Corey EJ, Su W, Pace-Asciak CR. Hepoxilin A3 induced changes in cytosolic calcium, intracellular $\mathrm{pH}$ and membrane potential in human neutrophils. Biochem $J$ (1990) 266:63-8.

53. Mumy KL, Bien JD, Pazos MA, Gronert K, Hurley BP, McCormick BA. Distinct isoforms of phospholipase A2 mediate the ability of Salmonella enterica serotype typhimurium and Shigella flexneri to induce the transepithelial migration of neutrophils. Infect Immun (2008) 76:3614-27. doi:10.1128/ IAI.00407-08

54. Boll EJ, Struve C, Sander A, Demma Z, Krogfelt KA, McCormick BA. Enteroaggregative Escherichia coli promotes transepithelial migration of neutrophils through a conserved 12-lipoxygenase pathway. Cell Microbiol (2012) 14:120 32. doi:10.1111/j.1462-5822.2011. 01706.x

55. Boll EJ, Struve C, Sander A, Demma Z, Nataro JP, McCormick BA, et al. The fimbriae of enteroaggregative Escherichia coli induce epithelial inflammation in vitro and in a human intestinal xenograft model. J Infect Dis (2012) 206:714-22. doi: 10.1093/infdis/jis417

56. Hurley BP, Siccardi D, Mrsny RJ, McCormick BA. Polymorphonuclear cell transmigration induced by Pseudomonas aeruginosa requires the eicosanoid hepoxilin A 3 . Mian Yi Xue Za Zhi (2004) 173: 5712-20.

57. Hurley BP, Pirzai W, Mumy KL, Gronert K, McCormick BA. Selective eicosanoid-generating capacity of cytoplasmic phospholipase A2 in Pseudomonas aeruginosa-infected epithelial cells. Am J Physiol Lung Cell Mol Physiol (2011) 300: L286-94. doi:10.1152/ajplung. 00147.2010

58. Hajishengallis G, Darveau RP Curtis MA. The keystonepathogen hypothesis. Nat Rev Microbiol (2012) 10:717-25. doi:10.1038/nrmicro2873

59. Maloy KJ, Powrie F. Intestinal homeostasis and its breakdown in inflammatory bowel disease. Nature (2011) 474:298-306. doi:10.1038/ nature 10208

60. Serhan CN, Petasis NA. Resolvins and protectins in inflammation resolution. Chem Rev (2011) 111:5922-43. doi:10.1021/cr100396c

61. Fierro IM, Colgan SP, Bernasconi G, Petasis NA, Clish CB, Arita M, et al. Lipoxin A4 and Aspiring-triggered 15-epi-lipoxin A4 inhibit human neutrophil migration: comparisons between synthetic 15 epimers in chemotaxis and transmigration with microvessel endothelial cells and epithelial cells. J Immunol (2003) 170:2688-94.

62. Norling LV, Dalli J, Flower RJ, Serhan CN, Perretti M. Resolvin D1 limits polymorphonuclear leukocytes recruitment to inflammatory loci: receptor-dependent actions. Arterioscler Thromb Vasc Biol (2012). Available from: http://www.ncbi.nlm.nih.gov/ pubmed/22499990 doi:10.1161/ ATVBAHA.112.249508

63. Campbell EL, MacManus CF, Kominsky DJ, Keely S, Glover LE, Bowers BE, et al. Resolvin E1-induced intestinal alkaline phosphatase promotes resolution of inflammation through LPS detoxification. PNAS (2010) 107(32):14298-303.

Conflict of Interest Statement: The authors declare that the research was conducted in the absence of any commercial or financial relationships that could be construed as a potential conflict of interest.

Received: 20 May 2013; paper pending published: 12 June 2013; accepted: 15 July 2013; published online: 31 July 2013. Citation: Szabady RL and McCormick $B A$ (2013) Control of neutrophil inflammation at mucosal surfaces by secreted epithelial products. Front. Immunol. 4:220. doi: 10.3389/fimmu.2013.00220 This article was submitted to Frontiers in Mucosal Immunity, a specialty of Frontiers in Immunology.

Copyright (c) 2013 Szabady and McCormick. This is an open-access article distributed under the terms of the Creative Commons Attribution License (CC BY). The use, distribution or reproduction in other forums is permitted, provided the original author(s) or licensor are credited and that the original publication in this journal is cited, in accordance with accepted academic practice. No use, distribution or reproduction is permitted which does not comply with these terms. 